\title{
O Uso do Brinquedo Terapêutico no Processo de Vacinação
}

\author{
The use of Therapeutic Toy in the Vaccination Process
}

\author{
El uso del juguete terapéutico en el proceso de vacunación
}

\section{Renata Mendes Lima Juliani ${ }^{*}$, Alessandra da Silva Souza ${ }^{2}$}

Como citar esse artigo. Juliani, RML; Souza, AS. O Uso do Brinquedo Terapêutico no Processo de Vacinação. Revista Pró-UniverSUS. 2019 Jan./Jun.; 10 (1): 47-50.

\author{
Resumo
}

O presente estudo tem como objetivo descrever o uso do Brinquedo Terapêutico no preparo de pré-escolares no processo de vacinação. Trata-se de uma pesquisa exploratória com abordagem qualitativa, aprovada pelo Comitê de ética em Pesquisa (CEP) da Universidade de Vassouras (UV) sob o número 2.904.498. O cenário escolhido foi às salas de vacina de duas Unidades Básica de Saúde localizada no município de Vassouras/RJ. A coleta de dados ocorreu através da sessão de brinquedo terapêutico e do registro dos dados em um roteiro de observação e um diário de campo, no período correspondente ao mês de julho a setembro do ano 2018. Os comportamentos de cooperação e aceitação foram mais freqüentes no grupo experimental, enquanto os de menor aceitação e agressão foram observados no grupo controle. Conclui-se que a inserção do Brinquedo Terapêutico na rotina da atenção básica mostra-se uma proposta eficaz na busca de uma humanização assistencial nos serviços de atenção primária uma vez que possibilita uma melhor preparação da criança frente aos procedimentos dolorosos amenizando o medo e a ansiedade desenvolvidos na criança.

Palavras-chave: Enfermagem pediátrica, Jogos e brinquedos, Saúde Pública, Injeções intramusculares.

\begin{abstract}
The present study aims to describe the use of Therapeutic Toy in the preparation of pre-school children who will be vaccinated. This is an exploratory research with a qualitative approach, approved by the Research Ethics Committee (CEP) of the University of Vassouras (UV) under number 2,904,498. The scenario chosen was the vaccine rooms of two Basic Health Units located in the city of Vassouras / RJ. Data collection took place through the therapeutic toy session and data recording in an observation script and field diary, in the period corresponding to the month of July to September of the year 2018. The cooperation and acceptance behaviors were more frequent in the experimental group, while those of lesser acceptance were observed in the control group. It is concluded that the insertion of the Therapeutic Toy in the routine of basic care shows an effective proposal in the search for a humanization of care in the primary care services since it allows a better preparation of the child against painful procedures in the context of immunization, in addition to alleviating the fear and anxiety developed in the child.
\end{abstract}

Keywords: Pediatric nursing, Games and toys, Public Health, Intramuscular injections.

\section{Resumen}

El presente estudio tiene como objetivo describir el uso del Juguete Terapéutico en la preparación de preescolares que serán vacunados. Se trata de una investigación exploratoria con enfoque cualitativo, aprobada por el Comité de ética en Investigación (CEP) de la Universidad de Escobas (UV) bajo el número 2.904.498. El escenario escogido fue a las salas de vacunación de dos Unidades Básica de Salud ubicada en el municipio de Vassouras / RJ. La recolección de datos ocurrió a través de la sesión de juguete terapéutico y del registro de los datos en un itinerario de observación y un diario de campo en el período correspondiente al mes de julio a septiembre del año 2018. Los comportamientos de cooperación y aceptación fueron más frecuentes en el mismo, grupo experimental, mientras que los de menor aceptación fueron observados en el grupo control. Se concluye que la inserción del Juguete Terapéutico en la rutina de la atención básica se muestra una propuesta eficaz en la búsqueda de una humanización asistencial en los servicios de atención primaria ya que posibilita una mejor preparación del niño frente a procedimientos dolorosos en el contexto de la inmunización, además de amenizar el miedo y la ansiedad desarrollados en el niño.

Palabras clave: Enfermería pediátrica, Juegos y juguetes, Salud pública, Inyecciones intramusculares. 


\section{Introdução}

Durante nossa experiência nos estágios nas Unidades Básicas de Saúde (UBS), evidenciamos como as crianças submetidas à vacinação apresentavam tensão, medo e ansiedade expressos através de choro e de movimentos de luta para fugir dessa situação "amedrontadora e ameaçadora" a seu corpo, assim gerando dificuldades a enfermagem para executar esse cuidado. Essas dificuldades podem ser intensificadas devido à falta de preparo adequado do pré-escolar a ser submetido à vacinação.

Atuar como enfermeiro em cada fase do desenvolvimento humano é extremamente desafiador, pois é necessário aguçar sentidos para compreender as necessidades humanas do paciente/cliente da fase específica da vida em que se encontra. Esse desafio é redobrado quando cuidamos de crianças em idade préescolar (3-6 anos), pois as mesmas tendem a apresentar um pensamento fantasioso e egocêntrico, além de possuírem noção pouco estabelecida de seus limites corporais e de sua estrutura anatômica ${ }^{1}$.

O brincar é um dos aspectos mais significantes na vida da criança. A atividade lúdica é essencial ao desenvolvimento infantil, pois é brincando que, desde os primeiros anos de vida, a criança relaciona-se com as pessoas à sua volta e o meio ambiente ${ }^{2}$.

A brincadeira pode ser classificada em dois tipos: (1) Recreacional: definida como atividade não estruturada, onde a criança apresenta uma participação espontânea, a fim de obter prazer e promover interação entre as crianças; e (2) Terapêutica: definida como atividade estruturada, conduzida por profissionais capacitados para aplicar o brinquedo terapêutico, a fim de promover o bem-estar físico e emocional da criança que vivencia uma situação incomum à sua idade ${ }^{3}$.

Desta forma, podemos afirmar que o brincar é um direito de toda criança e serve como instrumento permitindo a expressão e a elaboração dos seus próprios conflitos diante da situação vivenciada, servindo como suporte para que a criança atinja seu desenvolvimento emocional e cognitivo, facilitando a assimilação e entendimento de muitos conceitos. Na assistência à saúde, o brincar deve ser utilizado tanto para cumprir sua função recreacional como terapêutica, destacandose para tanto o Brinquedo Terapêutico.

$\mathrm{O}$ brinquedo terapêutico (BT) constitui-se em um brinquedo estruturado para a criança aliviar a ansiedade causada por experiências atípicas para a idade, que costumam ser ameaçadoras e requerem mais do que recreação para resolver a angústia associada. É estruturado para a criança aliviar a tensão causada por experiências que são atípicas para sua idade e que são ameaçadoras assim requerendo mais do que recreação para aliviar a ansiedade. Deve ser utilizado sempre que a criança tiver dificuldade em compreender ou lidar com uma experiência ameaçadora, difícil ou necessitar ser preparada para procedimentos ${ }^{4}$.

O BT pode ser classificado em três tipos de acordo com sua finalidade e intenção de uso: Brinquedo Terapêutico Dramático ou Catártico, Brinquedo Terapêutico Instrucional e Brinquedo Terapêutico Capacitador de Funções Fisiológicas ${ }^{3}$.

No que tange às imunizações, o estresse e o temor relacionados às aplicações das vacinas e à sensação dolorosa são motivos de ansiedade para crianças das mais diversas faixas etárias, configurando-se, em alguns momentos, em tarefa extremamente penosa aplicar a vacinação com a colaboração da criança ${ }^{5}$.

No âmbito da atenção básica, onde se desenvolve as ações da Estratégia Saúde da Família (ESF), a assistência integral e humanizada para promoção da saúde da criança, apesar das limitações, configurase como um dos objetivos principais ${ }^{5}$. Desta forma o Brinquedo Terapêutico mostra-se uma ferramenta eficaz a ser utilizada no contexto dos programas da atenção básica que envolvem a assistência à saúde da criança.

Os enfermeiros utilizam o BT com o objetivo de dar uma melhor compreensão de suas necessidades, tendo a função de auxiliar no preparo da criança que será submetida a procedimentos, assim permitindo com que a criança descarregue sua ansiedade, seus medos, angústias, sua tensão ao dramatizar as situações vivenciadas e manusear os instrumentos utilizados ou brinquedos que os representam. Assim o brinquedo normal se transforma em terapêutico quando proporciona o bem-estar psicofisiológico da criança e auxilia na comunicação enfermeiro-criança durante o preparo para um procedimento doloroso ${ }^{4}$.

A utilização do BT por enfermeiros na assistência é regulamentada pela resolução $n^{\circ} 546 / 2017$. O seu uso segue as novas tendências filosóficas do cuidado à criança buscando prestar uma assistência atraumática que pressupõe intervenções voltadas a eliminar ou reduzir os desconfortos físicos e psicológicos experenciados pela criança e seus familiares ${ }^{6}$.

Neste contexto esta pesquisa tem como objetivos: descrever o uso do Brinquedo Terapêutico no preparo de crianças pré-escolares para vacinação e identificar os com-portamentos apresentados por crianças na aplicação da vacina após o preparo com o BT e o comportamento daquelas que não receberam o preparo com o brinquedo.

\section{Metodologia}

Trata-se de um estudo de caráter exploratório com abordagem qualitativa. $\mathrm{O}$ cenário escolhido para esta pesquisa foram as salas de vacinação de 2 (duas) Unidades Básicas de Saúde (UBS) localizadas no 
município de Vassouras/RJ, onde ocorreu o processo de administração de imunobiológicos injetáveis por via intramuscular.

Os sujeitos da pesquisa foram 10 pré-escolares observados durante o processo de vacinação por via intramuscular, no período de Julho a Outubro de 2018. Todos os pais ou responsáveis foram informados através de um Termo de Consentimento Livre e Esclarecido sobre os objetivos da pesquisa.

O presente estudo foi submetido à aprovação do Comitê de ética em Pesquisa (CEP) da Universidade de Vassouras (UV) para avaliação dos princípios éticos da pesquisa com seres humanos, autorizado sob o número 2.904.498. A pesquisa foi realizada conforme a resolução $n^{\circ}$ 466/2012 do Conselho Nacional de Saúde - MS, que regulamenta as normas de Pesquisa envolvendo Seres Humanos.

Os dados foram coletados por meio da observação da criança durante a vacinação. Para registro dos dados, utilizou-se um Roteiro de Observação e os registros feitos em um diário de campo com dados de identificação da criança e reações apresentadas durante o processo de vacinação.

As crianças observadas foram divididas em dois grupos: $\mathrm{O}$ grupo vacinar brincando - que foi o grupo experimental, onde as crianças foram preparadas com o BT; e o grupo controle - com crianças que não foram preparadas com o BT.

A leitura do material e análise dos dados foi produzida de acordo com a metodologia e à luz da Análise do Conteúdo, pelo fato deste método defender a descrição objetiva, sistematizada e quantitativa do conteúdo manifesto das comunicações para interpretação dos dados.7

Este artigo é parte integrante de um trabalho de conclusão de curso de Enfermagem da Universidade de Vassouras (UV).

\section{Resultados e Discussão}

Analisando as características das crianças do estudo constatou-se a predominância no sexo masculino. No grupo Controle, $(3 ; 60 \%)$ eram do sexo masculino e $(2 ; 40 \%)$ do sexo feminino e, no grupo Vacinar Brincando $(4 ; 80 \%)$ eram do sexo masculino e $(1 ; 20 \%)$ do sexo feminino. Em consonância com esses resultados em um estudo realizado sobre a utilização do BT no preparo da criança para a vacinação, foi verificado uma distribuição muito próxima quanto ao sexo, com discreta predominância do sexo masculino. 5

Quanto à faixa etária das crianças, verificamos que houve uma variação entre 4 anos e 2 meses e 4 anos e 7 meses. Um dos estágios do desenvolvimento mais beneficiados com a utilização do BT é o pré-escolar, que compreende a faixa etária entre 3 e 6 anos, quando predomina o pensamento mágico. 8
As sessões de BT foram realizadas de forma individual. A pesquisadora contava a história lúdica, demonstrava o procedimento na boneca e solicitava a participação da criança que, ao final da dramatização, era convidada a repetir a brincadeira.

Já as crianças do grupo controle e seus acompanhantes eram levados diretamente à sala de vacinação, acompanhadas pela pesquisadora, que também observava os comportamentos das crianças durante o procedimento.

Sobre as reações apresentadas pelas crianças durante a aplicação da vacina, podemos destacar os comportados de agressão que foram observadas somente no grupo controle. Desta forma podemos inferir que $100 \%$ das crianças observadas apresentaram os comportamentos de puxar o braço e esconder-se e apenas uma criança chutou. Nenhumas das crianças observadas tiveram comportamentos de bater, como pode ser observado na Tabela 1 a seguir:

Tabela 1. Distribuição das crianças segundo Comportamentos de Agressão

\begin{tabular}{|c|c|c|}
\hline & \multicolumn{2}{|c|}{ CONTROLE } \\
\hline $\begin{array}{c}\text { COMPORTAMENTOS } \\
\text { DE AGRESSÃo }\end{array}$ & $\mathbf{n}$ & Percentual \\
\hline Bater & & $(\%)$ \\
\hline Chutar & 0 & $0 \%$ \\
\hline Puxar o braço & 1 & $20 \%$ \\
\hline Esconder-se & 5 & $100 \%$ \\
\hline
\end{tabular}

Fonte: Dados da pesquisa do autor, 2018.

Em uma pesquisa realizada com pré escolares esses comportamentos também foram mais frequentes no grupo controle, onde as crianças não receberam o preparo com o brinquedo terapêutico, igualmente às da presente pesquisa. As crianças não colaboravam, chutavam, escondiam-se, gritavam e adotavam comportamento protetor'.

A tabela 2 apresenta os comportamentos de expressão Verbal que predominaram no grupo Controle foram: Gritar $(5 ; 100 \%)$, ameaçar $(1 ; 20 \%)$, solicitar interrupção do procedimento $(2 ; 40 \%)$ e negar o procedimento tentando evitá-lo $(3 ; 60 \%)$. Quanto às reações envolvendo a expressão verbal, todas as crianças do grupo Vacinar Brincando permaneceram quietas durante o procedimento.

Em um estudo realizado com crianças hospitalizadas identificou-se que o Brinquedo Terapêutico foi efetivo como estratégia de diminuir a tensão e a dor da criança no momento d realização dos procedimentos. Desta forma podemos inferior 
Tabela 2. Distribuição das crianças segundo Comportamentos de Expressão Verbal.

\begin{tabular}{|c|c|c|}
\hline & \multicolumn{3}{|c|}{ CONTROLE } \\
\hline \multirow{2}{*}{$\begin{array}{c}\text { COMPORTAMENTOS DE } \\
\text { EXPRESSÃO VERBAL }\end{array}$} & $\mathbf{n}$ & Percentual \\
\hline Grita & & $\mathbf{( \% )}$ \\
\hline Ameaça & 5 & $100 \%$ \\
\hline $\begin{array}{c}\text { Solicita intemupcão do } \\
\text { Procedimento }\end{array}$ & 2 & $20 \%$ \\
\hline Nega & 3 & $40 \%$ \\
\hline & Fonte: Dados da pesquisa do autor, 2018. \\
\hline
\end{tabular}

que a utilização do Brinquedo Terapêutico pode ser considerada um método usado a fim de auxiliar no processo de vacinação, orientando e educando quanto aos procedimentos realizados ${ }^{10}$.

\section{Conclusão}

Verificamos neste estudo que o Brinquedo Terapêutico é um valioso instrumento no preparo da criança para procedimentos, inclusive a vacinação. A inserção do BT na rotina da atenção básica mostrase uma proposta eficaz na busca de uma humanização assistencial nos serviços de atenção primária uma vez que possibilita uma melhor preparação da criança frente aos procedimentos dolorosos, no contexto da imunização, além de amenizar o medo e a ansiedade desenvolvidos na criança.

Os comportamentos de cooperação e aceitação foram mais frequentes no grupo experimental, enquanto os de menor aceitação e agressividade foram observadas apenas no grupo controle. O número ausente de comportamentos agressivos e de expressão verbal no grupo experimental reforçam os efeitos benéficos do BT no preparo da criança para vacinação.

Desta forma esses resultados permitiram ressaltar a importância do brincar e da utilização do BT no contexto assistencial dos pré-escolares no preparo da vacinação.

\section{Referências Bibliográficas}

1. Santos LMCN, Borba RIH, Sabatés AL. A importância do preparo da criança pré-escolar para a injeção intramuscular com uso do brinquedo. Acta Paul Enf, 2000 maio/ago.; 13(2).

2. Wong DL. Enfermagem pediátrica: elementos essenciais à intervenção efetiva.5 ed. Rio de Janeiro: Guanabara Koogan, 2018.

3. Cintra SMP, Silva CV, Ribeiro, C. A. O ensino do brinquedo/ brinquedo terapêutico nos cursos de Graduação em Enfermagem no Estado de São Paulo. Ver BrasEnferm 2006 jul-ago;59 (4): 497-501.

4. Ribeiro PJ, Sabatés AL, Ribeiro CA. Utilização do brinquedo terapêutico, como um instrumento de intervenção de Enfermagem, no preparo de crianças submetidas à coleta de sangue. Revescenferm USP, 2001 Dec.; 35(4).

5. Pontes JED et al. Therapeutic play: preparing the child for the vaccine. Einstein (São Paulo), 2015;13(2):238-42.

6. COFEN. Resolução $n^{0}$ 546, de 09 de maio de 2017. Dispõe sobre a utilização de técnica de brinquedo terapêutico pela Enfermagem. 2017.

7. Bardin L. Análise de Conteúdo. Lisboa. Edições 70. 2016.

8. Monroe RA. Promoção da saúde do pré-escolar. In: Hockenberry MJ, Wilson D, Winkelstein ML, editores. Wong fundamentos de enfermagem pediátrica. 8a ed. Rio de Janeiro: Elsevier; 2011. p. 449-64.

9. Martins MR, Ribeiro CA, Borba RIH, Silva CV. Protocolo de preparo da criança pré-escolar para punção venosa, com utilização do brinquedo terapêutico. Rev Latino-am Enfermagem. 2001 março; 9(2): 76-85.

10. Carvalho RL, Souza AS. A utilização do Brinquedo Terapêutico pelo Enfermeiro em Crianças Hospitalizadas. Re Pró-Universus Suplemento, 2014; 5(3). 